\title{
FLOOD MAPPING USING SYNTHETIC APERTURE RADAR: A CASE STUDY OF RAMSAR FLASH FLOOD
}

\author{
Ali Jamali ${ }^{1 *}$ and Alias Abdul Rahman ${ }^{2}$ \\ ${ }^{1}$ Faculty of Surveying Engineering, Apadana Institute of Higher Education, Shiraz, Iran- ali.jamali.65@ gmail.com \\ ${ }^{2}$ Universiti Teknologi Malaysia (UTM), Faculty of Geoinformation and Real Estate- alias@utm.my
}

KEY WORDS: Synthetic Aperture Radar, flooded area, mapping, Ramsar flash flood

\begin{abstract}
:
Disasters including flash floods, earthquakes, and landslides have huge economic and social losses besides their impact on environmental disruption. Studying environmental changes due to climate change can improve public and expert sector's awareness and response towards future disastrous events. Synthetic Aperture Radar (SAR) data and Interferometric Synthetic Aperture Radar (InSAR) technologies are valuable tools for flood modeling and surface deformation modeling. This paper proposes an efficient approach to detect the flooded area changes using Sentinel-1A over Ramsar flood on 5th October 2018. For detection of the flooded area due to flash flood SARPROZ in MATLAB programming language is used and discussed. Flooded areas in Ramsar are detected based on the change detection modeling using normalized difference values of amplitude belonging to the master image (on 28th September 2018) and the slave image (on 10th October 2018).
\end{abstract}

\section{INTRODUCTION}

Disasters cause devastating human and economic losses besides their environmental disruption. There are two types of Geo-hazards including natural hazards (such as landslides, earthquakes, floods, and tsunamis) and human-induced hazards (such as water contamination, land subsidence due to groundwater-extraction and atmosphere pollution) (Tomás and $\mathrm{Li}, 2017)$. Flood is a natural disaster that often causes a huge impact on infrastructures, people, and properties, as well as indirectly affecting on the country's economy (Ibrahim et al., 2017; Chang et al., 2008). Main reasons for flood include heavy and high-intensity rainfall, ineffective drainage system, and a high volume of runoff due to increasing impermeable ground surface (Sahoo and Sreeja, 2015).

Remote sensing data including satellite and airborne imagery and altimetry, are widely used to research floodplain inundation, floods, and river hydrodynamics for the last two decades (Schumann, 2017). In bad weather conditions in case of flooding events, Synthetic Aperture Radar (SAR) data due to its nature for penetrating through clouds are better choices over optical sensors. The surface deformation caused by geohazards including earthquakes, landslides, and floods, spaceborne interferometric synthetic aperture radar (InSAR) is a great method due to its high spatial resolution and its ability to acquire the data remotely, (Ferretti et al., 2001; Hooper, 2008).

For land monitoring of forests, water, soil, agriculture, emergency mapping support for natural disasters including flooding, landslide, earthquakes, Sentinel 1A, 1B satellites were launched. Sentinel 1 satellites carry a C-SAR sensor, which has medium and high-resolution imaging in allweather conditions. The C-SAR can obtain night imagery and detecting small movement on the ground, which makes it useful for land and sea monitoring. As Synthetic Aperture Radar (SAR) can provide frequent observations is particularly useful for flood mapping (Alsdorf et al., 2007; Mertes, 2002; Ward et al., 2014) due to its capability to monitor land in any weather conditions (Franceschetti and Lanari, 1999; Marzano et al., 2011; Schumann et al., 2009) and also in night-time (O'Grady et al., 2011; Waisurasingha et al., 2007; Wilson and Rashid, 2005).

For several decades, SAR has been used to extract information about floods based on the different methodologies such as unsupervised classification, active contour models and thresholding (Martinis et al., 2011; Horritt et al.,2001; Hostache et al.,2012; Pulvirenti et al., 2011; Pierdicca et al., 2013; Pulvirenti et al., 2013; Arnesen et al., 2013;). Considering image thresholding techniques, which sets as flooded all the pixels with a radar backscatter lower than a certain threshold value (Mason et al., 2012a, 2012b; Schumann et al., 2010; Townsend, 2002) shows reliable results.

In this research, for disaster monitoring/modeling, a case study of a flash flood based on the data of Sentinel 1A are presented and discussed. In this regard, SAR sensor satellites and InSAR technology for environmental monitoring and disaster management are presented. Following this Section, in Section 2, the study area is discussed. SAR data preprocessing is presented in Section 3. In Section 4, results of Ramsar flash flood detection is presented. Conclusion of this research is discussed in Section 5.

\section{STUDY AREA AND DATA COLLECTION}

On $5^{\text {th }}$ October 2018 heavy rain occurred in Ramsar in Mazandaran Province recorded $274.6 \mathrm{~mm}$ of rain in 24 hours continuing till $6^{\text {th }}$ October. The flash Flood caused extreme material damage causing six deaths in the province of Mazandaran. According to the Iranian Red Crescent Society (IRCS), in the northern province of Gilan, there was noticeable damage in six counties with two deaths reported in Gilan province. 
In total, 39 counties (154 towns and villages) have been affected by the flash flood with more than 660 damaged homes. Ramsar (see Figure 1) is located in the west of Mazandaran province of Iran. The annual average rainfall of the area is around $1200 \mathrm{~mm}$. July and August are the hottest months with a maximum temperature of $29^{\circ} \mathrm{C}$ where January is the coldest one with a minimum temperature of $3^{\circ} \mathrm{C}$.

For the study, two Single Looks Complex (SLC) of Sentinel $1 \mathrm{~A}$ one belonging to $28^{\text {th }}$ September 2018 (before flood in Ramsar) (see Figure 2a) and other one belonging to $10^{\text {th }}$ October 2018 (four days after the flash flood in Ramsar) (see Figure $2 b$ ) for change detection modelling based on the SAR data using SARPROZ in MATLAB programming language are used. Properties of utilized Sentinel 1-A SLC images for the Ramsar flash flood are presented in Table 1.

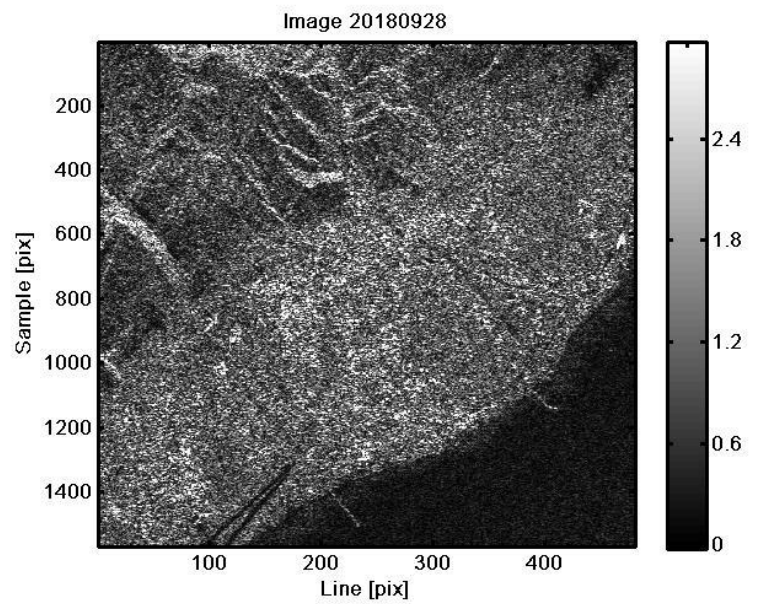

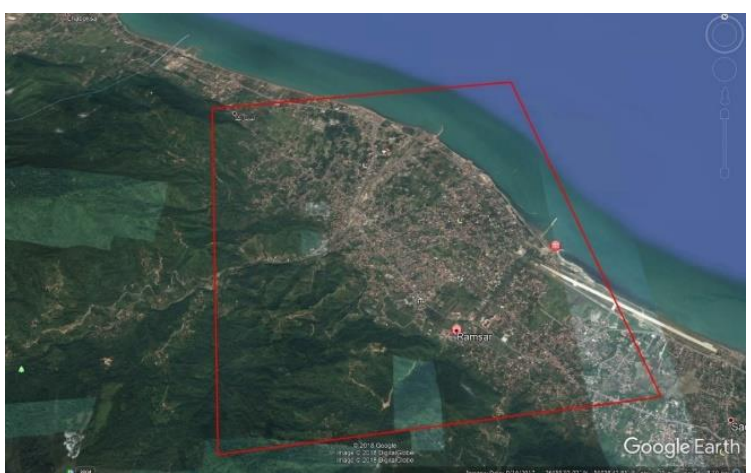

Figure 1. Study area (Ramsar) in Google Earth Pro.

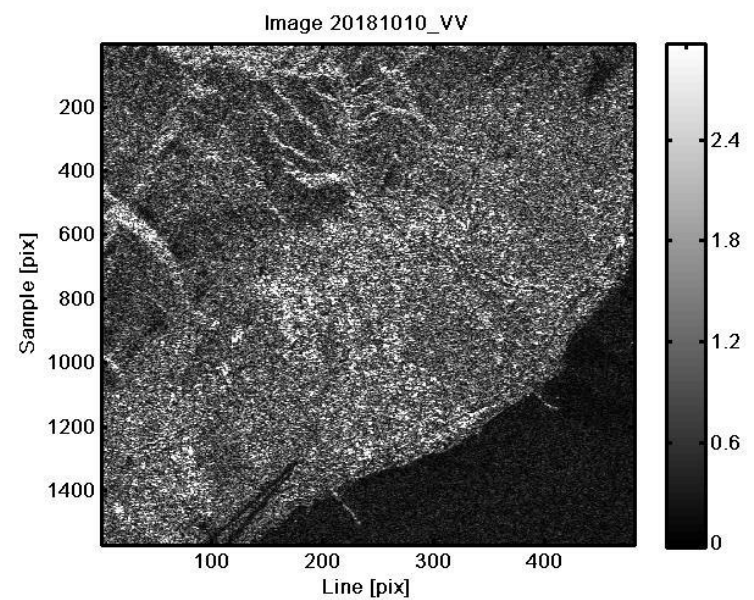

Figure 2. a) SLC Sentinel 1A image before the flash flood (left image, master image) b) SLC Sentinel 1A image after the flash flood (right image, slave image).

Table 1: Single Look Complex (SLC) of Sentinel-1A images properties of the study area.

\begin{tabular}{|l|l|l|l|l|}
\hline Granule SLC Name & Orbit & Acquisition Mode & $\begin{array}{l}\text { Acquisition } \\
\text { Date }\end{array}$ & Pass \\
\hline $\begin{array}{l}\text { S1A_IW_SLC_1SDV_20180928T143616_20180928T14 } \\
\text { 3643_023900_029BE2_92D2 }\end{array}$ & 23900 & IW & $2018-09-28$ & Ascending \\
\hline $\begin{array}{l}\text { S1A_IW_SLC_1SDV_20181010T143617_20181010T14 } \\
\text { 3644_024075_02A1A1_C0E9 }\end{array}$ & 24075 & IW & $2018-10-10$ & Ascending \\
\hline
\end{tabular}

\section{DATA PROCESSING}

As shown in Figure 3, for flood modeling, the master and the slave image are required to be co-registered using ground control points. Co-registration guarantees that each ground target is related to the same (range, azimuth) pixel in both the slave and the master images. (Figure 4). Co-registration will "align" all images pixel-by-pixel which allows for the comparison of the two images pixel-by-pixel.

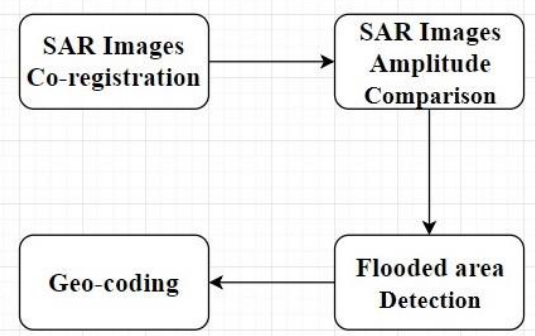

Figure 3. Workflow chart for flooded area detection caused

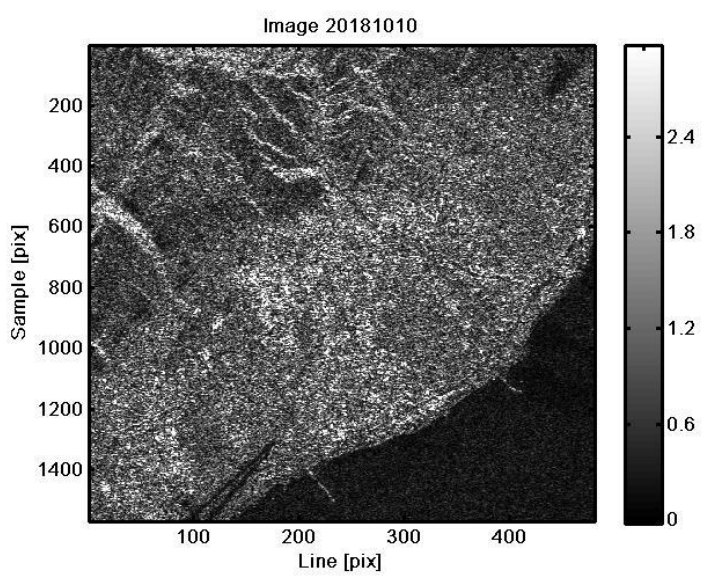

Figure 4. Co-registered image processed in SARPROZ in by Ramsar flood. 
The International Archives of the Photogrammetry, Remote Sensing and Spatial Information Sciences, Volume XLII-4/W16, 2019 6th International Conference on Geomatics and Geospatial Technology (GGT 2019), 1-3 October 2019, Kuala Lumpur, Malaysia

In the pre-processing phase, Reflectivity map and amplitude stability Index are calculated (see Figure 5). For the mask for sparse point selection, local maxima algorithm is used.

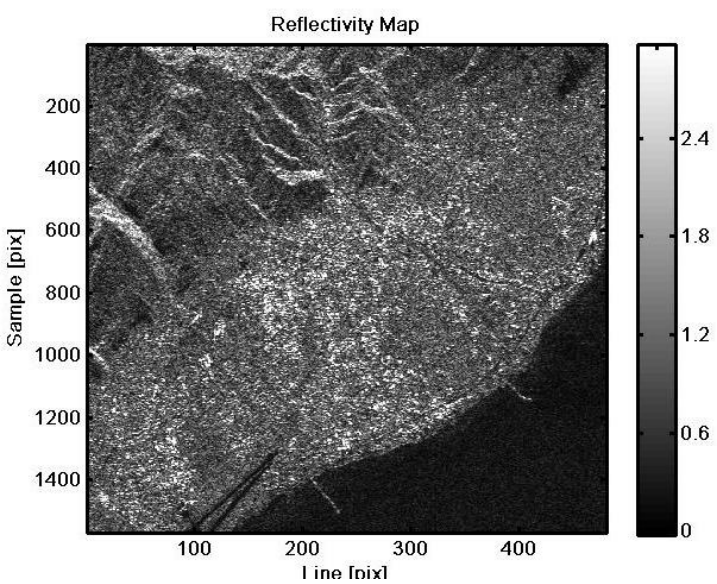

Figure 5. Reflectivity map processed in SARPROZ in MATLAB.

\section{RESULTS}

For flood modeling, the difference between the intensity of the two SAR images is required to be calculated. Amplitude values of the slave and the master images are compared, and their normalized difference with filter window of 5 and threshold of 0.3 is calculated (values below 0.3 would be considered as zero) (see Figure 6). A positive value (red) means the slave image intensity is greater than the master image and a negative value (blue) means the slave image is smaller than the master image.

For flood modeling, the intensity of the slave image should be smaller than the master image. Values of higher than zero are required to be cut out in a resampling process. Figures 6 and 7 show flooded areas in Ramsar based on the change detection modeling using normalized difference values of amplitude belonging to the master image (on 28th September 2018) and the slave image (on 10th October 2018).

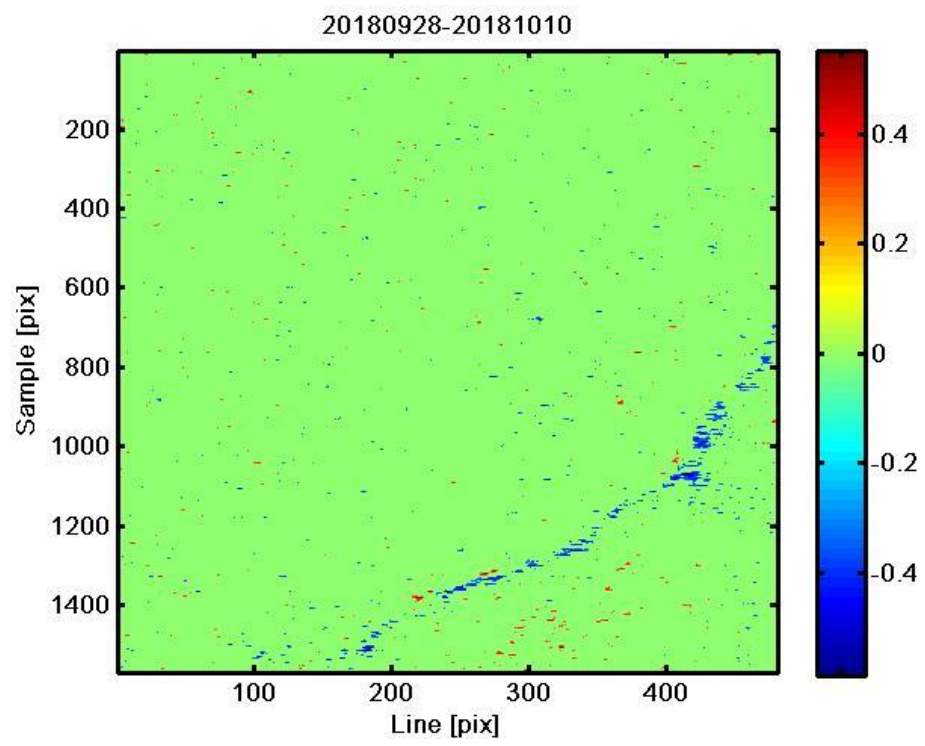

Figure 6. Change detection modelling from the normalized difference of amplitude values of the slave and the master images (blue color areas presents flooded regions).

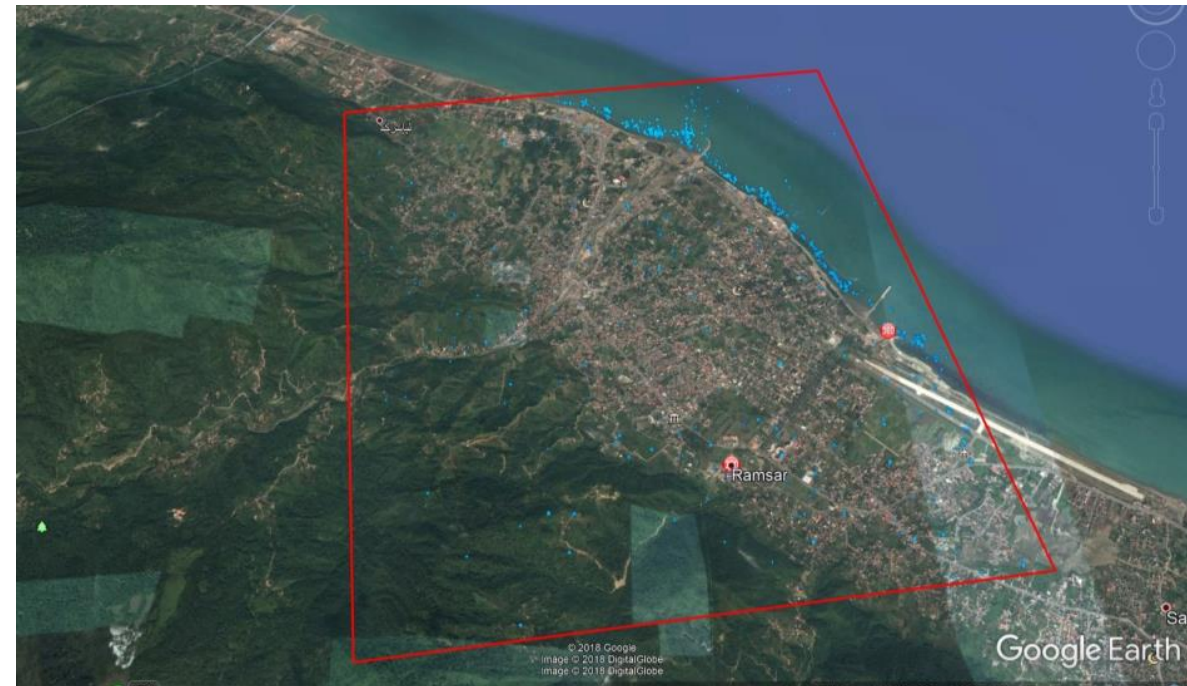

Figure 7. Flooded areas in Ramsar based on the change detection in Google Earth Pro processed in SARPROZ in MATLAB. 
The difference between the intensity of the two SAR images shows a minimum value of -0.5790 and a maximum value of 0.5624 in the study area of Ramsar from 28th September 2018 to 10 th October 2018.

Results of the difference between the intensity of the two SAR images before and after the Ramsar flood on 5th October 2018 show 6321 pixels with a negative value (flooded areas) and 2886 pixels with a positive value. Considering a spatial resolution of 2.3 meters by 14.1 meters for Sentinel 1-A SLC IW images, an area of $204990.03 \mathrm{~m} 2$ $(0.205 \mathrm{~km} 2)$ in Ramsar has been affected by the Ramsar flash flood.

\section{CONCLUSIONS}

In this research, use of the SAR data of Sentinel 1A for the heavy rain on $5^{\text {th }}$ October 2018 in Ramsar is discussed. The normalized difference of amplitude values of the two SAR images belonging to before (the master image) and after (the slave image) the flash flood was used to model flooded areas in Ramsar in Mazandaran Province of Iran.

Geoinformation derived from Earth observation (EO) plays a key role for detecting, analyzing and monitoring landslides to assist hazard and risk analysis. Free and commercial Earth Observation (EO) satellites sensor data are a key factor for large area environmental monitoring. Due to several climate change phenomena (e.g., increase of temperature due to greenhouse gasses, droughts) in recent years and their impact on the environment causing disasters such as flash floods and earthquakes, use of SAR satellite sensors is valuable information sources for monitoring current and to predict future disastrous phenomena.

\section{REFERENCES}

Chang L., Lin C., and Su M. (2008). Application of Geographic Weighted Regression to Establish Flood-damage Functions Reflecting Spatial Variation, Water SA, 34(2), 2008, pp. 209216.

European Space Agency. (2016). Interferometry Tutorial. Available

https://sentinel.esa.int/web/sentinel/toolboxes/sentinel-

$1 /$ tutorials.

Ferretti, A., Prati, C., \& Rocca, F. (2001). Permanent scatterers in SAR interferometry. IEEE Transactions on Geoscience and remote sensing, 39(1), 8-20.

He, C., Liu, X., Kang, C., Chen, D., \& Liao, M. (2017). Attribute Learning for SAR Image Classification. ISPRS International Journal of Geo-Information, 6(4), 111.

Hooper, A. (2008). A multi- temporal InSAR method is incorporating both persistent scatterer and small baseline approaches. Geophysical Research Letters, 35(16).

Ibrahim N.F., Zardari N.H., Shirazi S.M., Mohd Haniffah M.R., Mat Talib, S., Yusop Z. and Mohd Yusoff S.M.A. (2017). Identification of Vulnerable Areas to Floods in Kelantan River Sub-basins by using Flood Vulnerability Index, International Journal of GEOMATE, Vol. 12, Issue 29, 2017, pp. 107-114.
Li, S. Z. (2009). Markov random field modeling in image analysis. Springer Science \& Business Media.

Sahoo, S. N., \& Sreeja, P. (2015). Development of Flood Inundation Maps and quantification of flood risk in an Urban catchment of Brahmaputra River. ASCE-ASME Journal of Risk and Uncertainty in Engineering Systems, Part A: Civil Engineering, 3(1), A4015001.

Schumann, G. J.-P. (2017). Remote Sensing of Floods (Vol. 1). Oxford University Press.1-31 https://doi.org/10.1093/acrefore/9780199389407.013.265.

Tomás, R., \& Li, Z. (2017). Earth observations for geohazards: Present and future challenges.

Qu, Chunyan, Ronghu Zuo, Xinjian Shan, Jyr-ching Hu, and Guohong Zhang. 2017. "Coseismic Deformation of the 2016 Taiwan Mw6.3 Earthquake Using InSAR Data and Source Slip Inversion." Journal of Asian Earth Sciences 148 (October): 96104. https://doi.org/10.1016/j.jseaes.2017.08.027.

Chen, Qiang, Haiqin Cheng, Yinghui Yang, Guoxiang Liu, and Liyao Liu. 2014. "Quantification of Mass Wasting Volume Associated with the Giant Landslide Daguangbao Induced by the 2008 Wenchuan Earthquake from Persistent Scatterer InSAR." Remote Sensing of Environment 152 (September): 125-35. https://doi.org/10.1016/j.rse.2014.06.002.

Alsdorf, D.E., Rodriguez, E., Lettenmaier, D.P., 2007. Measuring surface water from space. Rev. Geophys. 45 (2), 1 24. INTRODUCTION

Mertes, L.A.K., 2002. Remote sensing of riverine landscapes. Freshw. Biol. 47 (4), 799-816. http://dx.doi.org/10.1046/j.13652427.2002.00909.x.

Ward, D.P., Petty, A., Setterfield, S.A., Douglas, M.M., Ferdinands, K., Hamilton, S.K., Phinn, S., 2014. Floodplain inundation and vegetation dynamics in the Alligator Rivers region (Kakadu) of northern Australia assessed using optical and radar remote sensing. Remote Sens. Environ. 147, 43-55. http://dx.doi.org/10.1016/j.rse.2014. 02.009.

Franceschetti, G., Lanari, R., 1999. Synthetic Aperture Radar Processing. CRC press.

Marzano, F.S., Mori, S., Weinman, J.A., Montopoli, M., 2011. Modeling polarimetric response of spaceborne synthetic aperture radar due to precipitating clouds from X- to Ka-band. IEEE Trans. Geosci. Remote Sens. 50 (3), 687-703. http://dx.doi.org/10. 1109/TGRS.2011.2163942.

Schumann, G., Bates, P.D., Horritt, M.S., Matgen, P., Pappenberger, F., 2009. Progress in integration of remote sensing-derived flood extent and stage data and hydraulic $\begin{array}{llll}\text { models. } & \text { Rev. } & \text { Geophys. } & 47\end{array}$ http://dx.doi.org/10.1029/2008RG000274.

O'Grady, D., Leblanc, M., Gillieson, D., 2011. Use of ENVISAT ASAR Global Monitoring Mode to complement optical data in the mapping of rapid broad-scale flooding in Pakistan. Hydrol. Earth Syst. Sci. 15 (11), 3475-3494. http://dx.doi.org/10.5194/ hess-15-3475-2011.

Waisurasingha, C., Aniya, M., Hirano, A., Kamusoko, C., Sommut, W., 2007. Application of C-band Synthetic Aperture Radar Data and Digital Elevation Model to Evaluate the Conditions of Flood-affected Paddies: Chi River Basin, 
The International Archives of the Photogrammetry, Remote Sensing and Spatial Information Sciences, Volume XLII-4/W16, 2019 6th International Conference on Geomatics and Geospatial Technology (GGT 2019), 1-3 October 2019, Kuala Lumpur, Malaysia

Thailand. Asian Association on Remote Sensing, Proceedings ACRS.

Wilson, B.A., Rashid, H., 2005. Monitoring the 1997 flood in the Red River valley. Can. Geogr. 49 (1), 100-109.

Martinis, S., Twele, A., Voigt, S., 2011. Unsupervised extraction of flood-induced backscatter changes in SAR data using markov image modeling on irregular graphs. IEEE Trans. Geosci. Remote Sens. 49, 251-263. http://dx.doi.org/10.1109/TGRS.2010. 2052816.

Horritt, M.S., Mason, D.C., Luckman, a. J., 2001. Flood boundary delineation from synthetic aperture radar imagery using a statistical active contour model. Int. J. Remote Sens. 22 (October 2014), 2489-2507. http://dx.doi.org/10.1080/ 01431160152497691

Hostache, R., Matgen, P., Wagner, W., 2012. Change detection approaches for flood extent mapping: how to select the mostadequate reference image from online archives? Int. J. Appl. Earth Obs. Geoinf. 19 (1), 205-213. http://dx.doi.org/10.1016/j.jag. 2012.05.003.

Pulvirenti, L., Chini, M., Marzano, F.S., Pierdicca, N., Mori, S., Guerriero, L., ... Candela, L., 2012. Detection of floods and heavy rain using Cosmo-SkyMed data: the event in Northwestern Italy of November 2011. In: International Geoscience and Remote Sensing Symposium (IGARSS), (November 2011), pp. 3026-3029. http://dx.doi.org/ 10.1109/IGARSS.2012.6350788.

Pulvirenti, L., Pierdicca, N., Chini, M., Guerriero, L., 2013. Monitoring flood evolution in vegetated areas using cosmoskymed data: the tuscany 2009 case study. IEEE J. Sel. Top. Appl. Earth Obs. Remote Sens. 6 (4), 1807-1816. http://dx.doi.org/10.1109/ JSTARS.2012.2219509.

Arnesen, A.S., Silva, T.S.F., Hess, L.L., Novo, E.M.L.M., Rudorff, C.M., Chapman, B.D., McDonald, K.C., 2013. Monitoring flood extent in the lower Amazon River floodplain using ALOS/PALSAR ScanSAR images. Remote Sens. Environ. 130, 51-61. http://dx. doi.org/10.1016/j.rse.2012.10.035.

Pierdicca, N., Pulvirenti, L., Chini, M., Guerriero, L., Candela, L., 2013. Observing floods from space: experience gained from COSMO-SkyMed observations. Acta Astronaut. 84, 122-133. http://dx.doi.org/10.1016/j.actaastro.2012.10.034.

Mason, D.C., Davenport, I.J., Neal, J.C., Schumann, G.J.-P., Bates, P.D., 2012a. Near realtime flood detection in urban andruralareas usinghigh-resolution synthetic aperture radar images. IEEE Trans. Geosci. Remote Sens. 50 (8), 3041-3052. http://dx.doi. org/10.1109/TGRS.2011.2178030.

Mason, D.C., Schumann, G.J.P., Neal, J.C., Garcia-Pintado, J., Bates, P.D., 2012b. Automatic near real-time selection of flood water levels from high resolution Synthetic Aperture Radar images for assimilation into hydraulic models: acase study.

Schumann, G., Di Baldassarre, G., Alsdorf, D., Bates, P.D., 2010. Near real-time flood wave approximation on large rivers from space: application to the River Po, Italy. Water Resour. Res. 46 (5), 1-8. http://dx.doi.org/10.1029/2008WR007672.

Townsend, P.A., 2002. Estimating forest structure in wetlands using multitemporal SAR. Remote Sens. Environ. 79 (2-3), 288304. http://dx.doi.org/10.1016/S00344257(01)00280-2.

Atlas, D., Moore, R.K., 1987. The measurement of precipitation with synthetic aperture radar. J. Atmos. Ocean. Technol. 4 (3), 368-376.
http://dx.doi.org/10.1175/15200426(1987)004<0368:TMOPWS> 2.0.CO;2

Danklmayer, A., Chandra, M., 2009. Precipitation effects for Ka-band SAR. In: Proc. of Advanced RF Sensors For Earth Observation (ARSI). 1. pp. 1368-1370.

Jameson, A.R., Li, F.K., Durden, S.L., Haddad, Z.S., Holt, B., Fogarty, T., ... Moore, R.K., 1997. SIR-C/X-SAR observations of rain storms. Remote Sens. Environ. 59 (2), 267-279. http://dx.doi.org/10.1016/S0034-4257(96)00159-9.

Bragg, W., 1913. The diff raction of short electromagnetic waves by a crystal. Proc. Camb. Philos. Soc. 17, 43-57. http://dx.doi.org/10.1107/S0567739472000609.

Schaber, G.G., McCauley, J.F., Breed, C.S., 1997. The use of multifrequency and polarimetric SIR-C/X-SAR data in geologic studies of Bir Safsaf, Egypt. Remote Sens. Environ. 59 (2), 337 363. http://dx.doi.org/10.1016/S0034-4257(96)00143-5.

Franceschetti, G., Iodice, A., Riccio, D., 2002. A canonical problem in electromagnetic backscattering from buildings. IEEE Trans. Geosci. Remote Sens. 40 (8), 1787-1801. http://dx.doi.org/10.1109/TGRS.2002.802459.

Hong, S.H., Wdowinski, S., 2014. Double-bounce component in cross-polarimetric SAR from a new scattering target decomposition. IEEE Trans. Geosci. Remote Sens. 52 (6), 30393051. http://dx.doi.org/10.1109/TGRS.2013.2268853.

Jackson, T.J., Schmugge, J., Engman, E.T., 1996. Remote sensing applications to hydrology: soil moisture. Hydrol. Sci. J. 41 (4), 517-530. http://dx.doi.org/10.1080/ 02626669609491523.

Paloscia, S., Pettinato, S., Santi, E., Notarnicola, C., Pasolli, L., Reppucci, A., 2013. Soil moisture mapping using Sentinel-1 images: algorithm and preliminary validation. Remote Sens. Environ. 134, 234-248 http://dx.doi.org/10.1016/j.rse.2013.02.027.

Revised August 2019 